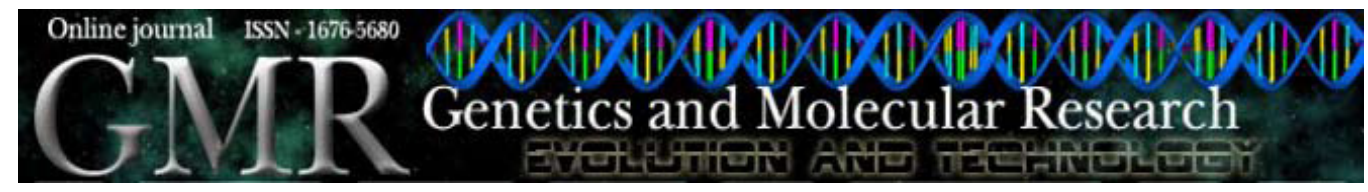

\title{
Lack of association between paraoxonase-1 Q192R polymorphism and rheumatoid arthritis in southeast Iran
}

\author{
M. Hashemi ${ }^{1,2}$, A.K. Moazeni-Roodi ${ }^{3}$, A. Fazaeli ${ }^{4}$, M. Sandoughi ${ }^{5}$, \\ G.R. Bardestani ${ }^{5}$, D.M. Kordi-Tamandani ${ }^{3}$ and S. Ghavami ${ }^{6}$ \\ ${ }^{1}$ Department of Clinical Biochemistry, School of Medicine, \\ Zahedan University of Medical Sciences, Zahedan, Iran \\ ${ }^{2}$ Cellular and Molecular Research Center, \\ Zahedan University of Medical Sciences, Zahedan, Iran \\ ${ }^{3}$ Department of Biology, Faculty of Sciences, \\ Sistam and Baluchistan University, Zahedan, Iran \\ ${ }^{4}$ Department of Parasitology, School of Medicine, \\ Zanjan University of Medical Sciences, Zanjan, Iran \\ ${ }^{5}$ Department of Internal Medicine, School of Medicine, \\ Zahedan University of Medical Sciences, Zahedan, Iran \\ ${ }^{6}$ Department of Physiology, Manitoba Institute of Child Health, \\ University of Manitoba, Winnipeg, Manitoba, Canada \\ Corresponding author: M. Hashemi \\ E-mail: mhd.hashemi@gmail.com; hashemim@zdmu.ac.ir
}

Genet. Mol. Res. 9 (1): 333-339 (2010)

Received November 3, 2009

Accepted November 30,2009

Published February 23, 2010

ABSTRACT. Decreased paraoxonase-1 (PON1) activity has been associated with rheumatoid arthritis. There are two polymorphisms in serum PON1; one differs in the amino acid at position 192 (Q192R) and the other one differs at position 55 (L55M). We looked for a possible association between Q192R polymorphism and rheumatoid arthritis. The Q192R polymorphism in 88 rheumatoid arthritis patients and 78 healthy subjects was determined using tetra amplification refractory mutation system-polymerase chain reaction (ARMS-PCR) and PCRrestriction fragment length polymorphism (RFLP) methods. We found 
no significant differences between rheumatoid arthritis patients and control subjects regarding PON1 Q192R polymorphism. PON1 Q192R polymorphism was not found to be correlated with increased risk for rheumatoid arthritis in this Iranian population.

Key words: Paraoxonase; PON1; Q192R polymorphism; Rheumatoid arthritis

\section{INTRODUCTION}

Rheumatoid arthritis (RA) is a chronic arthritic condition that can lead to deformities and disabilities. Although the exact pathogenesis of the disease is unknown, both genetic and environmental factors play key roles in this disease process (Deighton and Walker, 1991). It has been reported that reactive oxygen species (ROS) may play an important role in the pathogenesis of RA (Gambhir et al., 1997; Bauerova and Bezek, 1999). Under normal circumstances, relatively low concentrations of ROS are formed in all cells and tissues in oxidative processes, and a variety of antioxidative mechanisms serve to control their production. Under pathological conditions, the levels of ROS are altered by increased production and/or inadequate removal, which results in oxidative stress, inducing cell damage and lipid peroxidation (Halliwell, 1994; Gambhir et al., 1997).

Paraoxonase-1 (PON1) is coded by a gene located on chromosome 7q21.3-22.1 in a cluster with two similar genes, PON2 and PON3, whose physiological substrates are not yet identified (Primo-Parmo et al., 1996). PON1 consists of 354 amino acids with a molecular mass of $43 \mathrm{kDa}$ and is exclusively bound to high-density lipoprotein. PON1 is recognized as an antioxidant enzyme as it hydrolyzes lipid peroxides in oxidized lipoproteins (Blatter et al., 1993; Mackness et al., 1996; Aviram et al., 1998). PON1 also exerts paraoxonase and arylesterase activities, where it hydrolyzes organophosphates (paraoxon) and aromatic esters such as phenyl acetate (Gan et al., 1991).

PON1 activity has been reported to decrease in RA due to oxidative stress (Baskol et al., 2005; Isik et al., 2007). Paraoxonase activity is found to vary extensively among individuals, in part, due to the presence of polymorphisms. The PON1 gene has two common coding region polymorphisms causing a change from glutamine to arginine at the 192 position $(\mathrm{Q} / \mathrm{R} 192)$ and leucine to methionine at the 55 position (L/M 55), resulting in a change of both the level and activity of the enzyme (Humbert et al., 1993; Garin et al., 1997; Mackness et al., 1998; Aviram et al., 2000).

There are little data regarding the association between PON1 polymorphisms and RA. A significant difference in the distribution of PON1 Q192R polymorphisms was observed between RA patients and healthy subjects (Tanimoto et al., 2003). The aim of the present study was to determine the possible association between Q192R polymorphism and RA in an Iranian population.

\section{MATERIAL AND METHODS}

\section{Patients}

We studied a total of 88 patients ( 80 women and 8 men) with an average age of 45.5 years (minimum 17, maximum 75) fulfilling the American College of Rheumatology (ACR) criteria for RA (Arnett et al., 1988). All subjects were patients of the Rheumatology Clinic at Zahedan University of Medical Sciences. The control group consisted of 78 healthy individuals 
(57 women and 21 men) with a mean age of 45.4 years (minimum 23, maximum 77), who were unrelated to RA patients. The project was approved by the local Ethics Committee of Zahedan University of Medical Sciences, and informed consent was obtained from all patients and healthy individuals. Blood samples were collected in Na-EDTA tubes from patients and healthy controls.

\section{DNA extraction}

The Saremi et al. (2008) protocol was used to extract genomic DNA from whole blood with some minor modifications. Briefly, $500 \mu \mathrm{L}$ blood was transferred to $1.5-\mathrm{mL}$ microfuge tubes, and $1 \mathrm{~mL}$ cell lysis buffer (10 mM Tris- $\mathrm{HCl}, 11 \% \mathrm{w} / \mathrm{v}$ sucrose, $5 \mathrm{mM} \mathrm{MgCl}$, and $11 \% \mathrm{v} / \mathrm{v}$ Triton X-100) was added. Microfuge tubes were gently mixed and centrifuged for $2 \mathrm{~min}$ at $6000 \mathrm{rpm}$ at room temperature, after which the supernatant was discarded. The procedure was repeated twice. Next, $300 \mu \mathrm{L}$ buffer II (10 mM Tris-HCl, $10 \mathrm{mM}$ EDTA, and $10 \mathrm{mM}$ sodium citrate) and $40 \mu \mathrm{L} \mathrm{10 \%} \mathrm{SDS} \mathrm{were} \mathrm{added,} \mathrm{and}$ the mixture incubated for $2 \mathrm{~min}$ at room temperature. Then, $100 \mu \mathrm{L}$ saturated $\mathrm{NaCl}$ and $600 \mu \mathrm{L}$ chloroform were added with gentle mixing, and the mixture centrifuged for $2 \mathrm{~min}$ at $6000 \mathrm{rpm}$. The supernatant was transferred to a new microfuge tube, where $700 \mu \mathrm{L}$ cold isopropanol was added, followed by gentle mixing and centrifugation for $1 \mathrm{~min}$ at $12,000 \mathrm{rpm}$ for $2 \mathrm{~min}$ at $4^{\circ} \mathrm{C}$. The supernatant was discarded and $700 \mu \mathrm{L}$ cold $70 \%$ ethanol was added. The suspension was gently mixed and centrifuged for $1 \mathrm{~min}$ at $12,000 \mathrm{rpm}$ at $4^{\circ} \mathrm{C}$. Pellets were subsequently dried before dissolving in $100 \mu \mathrm{L}$ distilled water.

\section{Tetra primer amplification refractory mutation system}

The amplification refractory mutation system (ARMS) is a simple and rapid detection method of point mutation and small nucleotide insertion or deletion (Newton et al., 1989). In the present study, we designed a tetra primer ARMS for the detection of Q192R polymorphism of PON1 according to the Ye et al. (2001) procedure. The primers were designed according to the program accessible through the internet website; http://cedar.genetics.soton.ac.uk/ public_html/primer1.html.

We used two external primers (forward outer primer: 5'-TGTTCCATTATAGCTAG CACGA-3', reverse outer primer: 5'-TTTCACCCCCTGAAAAATTA-3') and two inner primers; (forward inner primer (A allele): 5'-TTTCTTGACCCCTACTTCCA-3'; reverse inner primer (G allele): 5'-CAAATACATCTCCCAGGCTC-3'). Product sizes were 303 bp for A allele and $233 \mathrm{bp}$ for $\mathrm{G}$ allele, while the product size of the two outer primers was $496 \mathrm{bp}$ as shown schematically in Figure 1.

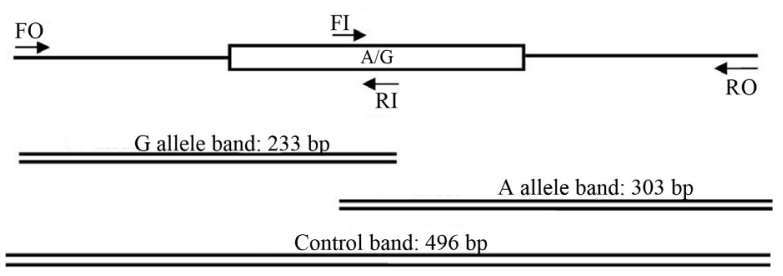

Figure 1. Schematic diagram of the tetra ARMS assay. Two forward and two reverse primers are used to generate three potential PCR products. Primers FO and RO give a 496-bp product, which is used for control of DNA quality and quantity. Primers FO and RI amplify the G (R) allele, generating a 233-bp product, and primers FI and RO generate a 303-bp product for the A (Q) allele. 
Reactions consisted of a total volume of $25 \mu \mathrm{L}$ containing $250 \mu \mathrm{M}$ dNTPs, $0.4 \mu \mathrm{M}$ of each primer, $1.5 \mathrm{mM} \mathrm{MgCl}, 1 \mathrm{U}$ Taq DNA polymerase (Roche Molecular Biochemicals, IN, USA), and $50 \mathrm{ng}$ genomic DNA. Polymerase chain reaction (PCR) cycling conditions were as follows: $5 \mathrm{~min}$ at $95^{\circ} \mathrm{C} ; 30$ cycles of $30 \mathrm{~s}$ at $95^{\circ} \mathrm{C}, 30 \mathrm{~s}$ at $55^{\circ} \mathrm{C}$ and $40 \mathrm{~s}$ at $72^{\circ} \mathrm{C} ; 10 \mathrm{~min}$ at $72^{\circ} \mathrm{C}$ (Corbett Research, Australia). Each reaction was verified on a $3 \%$ agarose gel.

\section{PCR-RFLP}

Determination of the PON1 Q192R polymorphism was carried out by PCR followed by restriction digestion (PCR-RFLP, restriction fragment length polymorphism). The primers used were: (forward: 5'-TGTTCCATTATAGCTAGCACGA-3' and reverse: 5'-TTTCACCCCCT GAAAAATTA-3'). The resulting PCR product size was $496 \mathrm{bp}$. The nucleotide substitution corresponding to position $192(\mathrm{Q} / \mathrm{R})$ creates a BSpPI (Biogen-Fermentas) restriction site. Digestion resulted in 287- and 209-bp fragments for the R allele (Figure 2B).

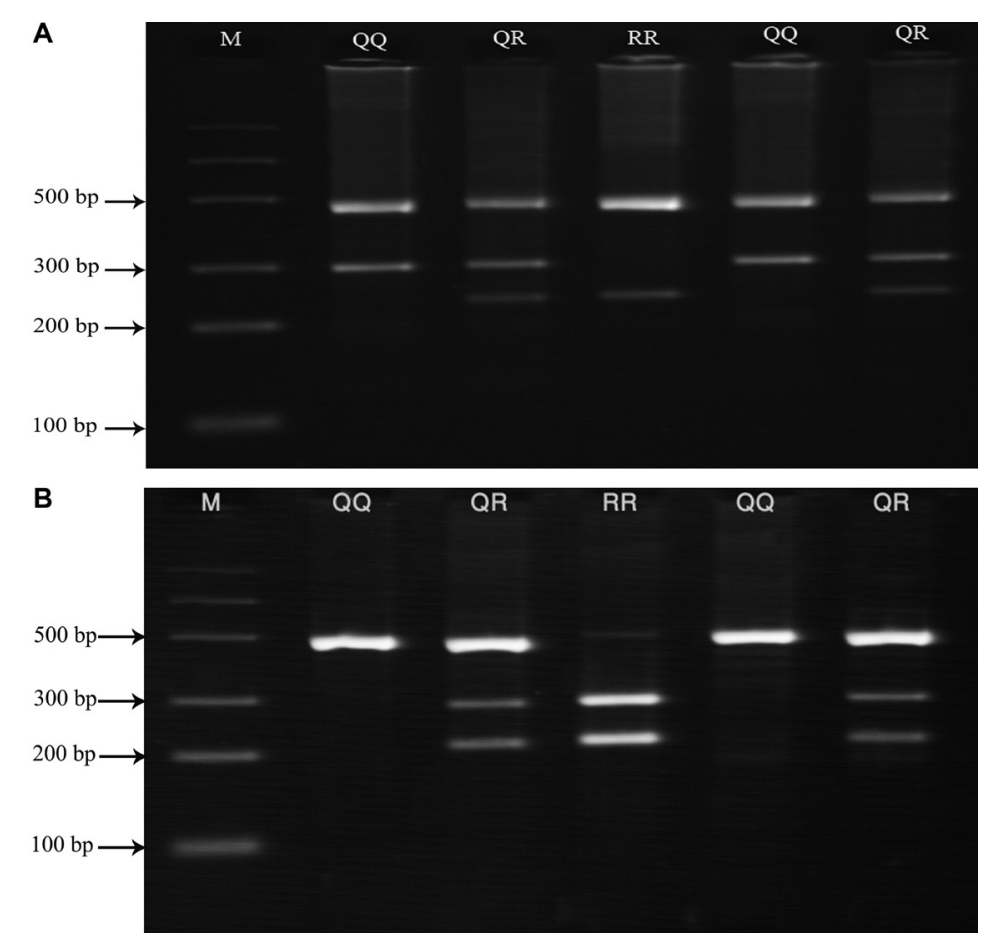

Figure 2. Results of tetra ARMS-PCR (A) and PCR-RFLP (B) of PON1 Q192R polymorphism. M = DNA marker.

\section{Statistical analysis}

Statistical analysis was performed using the SPSS 17.0 software. A chi-square test was used to determine the differences in the genotypes and allele frequencies between case and control groups. 


\section{RESULTS}

\section{Tetra primer ARMS-PCR}

The tetra primer ARMS-PCR method was effectively applied to determine the Q192R single-nucleotide polymorphism of PON1. The genotypes determined by this method were consistent with those determined by the PCR-RFLP method (Figure 2).

\section{Q192R PON1 polymorphism}

The distribution of Q192R polymorphism of PON1 in RA patients and normal subjects is shown in Table 1. The results showed that the wild-type genotype QQ was observed in $59.1 \%(52 / 88)$ of patients and $59.0 \%(46 / 78)$ of healthy subjects. There was no significant differences in genotypes of QQ between patients and normal subjects $(\mathrm{P}>0.05)$. As shown in Table 1, the frequencies of QR and RR did not differ between RA and normal individuals.

\begin{tabular}{|c|c|c|c|c|c|}
\hline Genotype & Rheumatoid arthritis & Healthy subjects & $95 \% \mathrm{CI}$ & OR & $P$ \\
\hline QQ & $59.1 \%(52 / 88)$ & $59.0 \%(46 / 78)$ & $0.541-1.868$ & 1.005 & NS \\
\hline QR & $20.5 \%(18 / 88)$ & $26.9 \%(21 / 78)$ & $0.395-1.650$ & 0.808 & NS \\
\hline $\mathrm{RR}$ & $20.5 \%(18 / 88)$ & $14.1 \%(11 / 78)$ & $0.688-3.562$ & 1.566 & NS \\
\hline
\end{tabular}

$\mathrm{NS}=$ nonsignificant.

The allele frequency of Q192R was not significantly different between RA and healthy subjects (Table 2). The results show that there was no association between PON1 Q192R polymorphism and RA in our population.

Table 2. Allele frequency of PON1 Q192R in rheumatoid arthritis and normal subjects.

\begin{tabular}{lcccr}
\hline Allele type & Rheumatoid arthritis & Healthy subjects & $95 \%$ CI & OR \\
\hline Q allele & $69.3 \%(122 / 176)$ & $72.4 \%(113 / 156)$ & $0.5344-1.383$ & 0.859 \\
R allele & $30.7 \%(64 / 176)$ & $27.6 \%(43 / 156)$ & $0.5718-1.512$ & 0.929 \\
\hline
\end{tabular}

$\mathrm{NS}=$ nonsignificant.

\section{DISCUSSION}

The association of PON1 gene polymorphism and risk of certain diseases has been documented (Sidoti et al., 2007; Leduc and Poirier, 2008; Agrawal et al., 2009; Leduc et al., 2009). In addition, PON1 gene polymorphisms (Q192R, L55M) alter both the level and activity of the enzyme (Humbert et al., 1993; Garin et al., 1997; Mackness et al., 1998; Aviram et al., 2000). In the present study, we found that there were no significant differences between RA and healthy subjects regarding Q192R polymorphism.

Rheumatoid arthritis is a progressive, relapsing autoimmune disease. Increased ROS and lipid peroxidation production, due to synovial inflammation, not only causes cellular damage but also increases oxidative stress. The main sources of ROS are activated phagocytes se- 
creting $\mathrm{O}_{2}{ }^{-}, \mathrm{H}_{2} \mathrm{O}_{2}$ and hypochlorite (Griffiths and Lunec, 1996). In RA cases, increased oxidative stress and decrease in antioxidants may have roles in both the pathogenesis of the disease (Nurcombe et al., 1991; Griffiths and Lunec, 1996) and the development of atherosclerosis (Sattar et al., 2003). Studies have shown that antioxidants are reduced in RA cases (McKeown et al., 1984; Jaswal et al., 2003; Isik et al., 2007).

Serum PON1 is a high-density lipoprotein-associated enzyme recognized as an antioxidant enzyme, since it hydrolyzes lipid peroxides in oxidized lipoproteins (Mackness et al., 1996; Aviram et al., 1998). It has been shown that PON1 hydrolyzes lipid peroxide products and $\mathrm{H}_{2} \mathrm{O}_{2}$ (Feingold et al., 1998) and contributes to the prevention of low-density lipoprotein oxidation (Miesel et al., 1996; Mackness et al., 1998; Shih et al., 1998; Popa et al., 2009). PON1 activity has also been suggested to be inversely associated with oxidative stress in serum and macrophages (Rozenberg et al., 2003). It has been shown that serum PON1 activity is significantly decreased in RA patients compared with healthy subjects (Maury et al., 1984; Tanimoto et al., 2003; Baskol et al., 2005). The decrease in PON1 activity in RA patients was found in every genotype $(\mathrm{Q} / \mathrm{Q}, \mathrm{Q} / \mathrm{R}, \mathrm{R} / \mathrm{R})$ of PON1 at $192 \mathrm{Q} / \mathrm{R}$. Furthermore, a difference in the distribution of PON1 Q/R polymorphisms was observed at position 192 between RA patients and healthy subjects. RA patients exhibited less (44\%) positive PON1-Q than did healthy subjects (66\%) (Tanimoto et al., 2003). This finding is inconsistent with our results. We found that the frequency of PON1-Q did not differ between RA (69.3\%) and normal subjects (72.4\%).

In conclusion, we found that there is no association between Q192R polymorphism of PON1 and rheumatoid arthritis and that PON1 Q192R polymorphism is not correlated with the risk for rheumatoid arthritis in our population.

\section{ACKNOWLEDGMENTS}

Research supported by Zahedan University of Medical Sciences. In addition, the authors would like to thank the patients and healthy subjects who willingly participated in the study.

\section{REFERENCES}

Agrawal S, Tripathi G, Prajnya R, Sinha N, et al. (2009). Paraoxonase 1 gene polymorphisms contribute to coronary artery disease risk among north Indians. Indian J. Med. Sci. 63: 335-344.

Arnett FC, Edworthy SM, Bloch DA, McShane DJ, et al. (1988). The American Rheumatism Association 1987 revised criteria for the classification of rheumatoid arthritis. Arthritis Rheum. 31: 315-324.

Aviram M, Rosenblat M, Bisgaier CL, Newton RS, et al. (1998). Paraoxonase inhibits high-density lipoprotein oxidation and preserves its functions. A possible peroxidative role for paraoxonase. J. Clin. Invest. 101: 1581-1590.

Aviram M, Hardak E, Vaya J, Mahmood S, et al. (2000). Human serum paraoxonases (PON1) Q and R selectively decrease lipid peroxides in human coronary and carotid atherosclerotic lesions: PON1 esterase and peroxidase-like activities. Circulation 101: 2510-2517.

Baskol G, Demir H, Baskol M, Kilic E, et al. (2005). Assessment of paraoxonase 1 activity and malondialdehyde levels in patients with rheumatoid arthritis. Clin. Biochem. 38: 951-955.

Bauerova K and Bezek A (1999). Role of reactive oxygen and nitrogen species in etiopathogenesis of rheumatoid arthritis. Gen. Physiol. Biophys. 18 (Spec No.): 15-20.

Blatter MC, James RW, Messmer S, Barja F, et al. (1993). Identification of a distinct human high-density lipoprotein subspecies defined by a lipoprotein-associated protein, K-45. Identity of K-45 with paraoxonase. Eur. J. Biochem. 211: 871-879.

Deighton CM and Walker DJ (1991). The familial nature of rheumatoid arthritis. Ann. Rheum. Dis. 50: 62-65.

Feingold KR, Memon RA, Moser AH and Grunfeld C (1998). Paraoxonase activity in the serum and hepatic mRNA levels decrease during the acute phase response. Atherosclerosis 139: 307-315. 
Gambhir JK, Lali P and Jain AK (1997). Correlation between blood antioxidant levels and lipid peroxidation in rheumatoid arthritis. Clin. Biochem. 30: 351-355.

Gan KN, Smolen A, Eckerson HW and La Du BN (1991). Purification of human serum paraoxonase/arylesterase. Evidence for one esterase catalyzing both activities. Drug Metab. Dispos. 19: 100-106.

Garin MC, James RW, Dussoix P, Blanche H, et al. (1997). Paraoxonase polymorphism Met-Leu54 is associated with modified serum concentrations of the enzyme. A possible link between the paraoxonase gene and increased risk of cardiovascular disease in diabetes. J. Clin. Invest. 99: 62-66.

Griffiths HR and Lunec J (1996). The Clq binding activity of IgG is modified in vitro by reactive oxygen species: implications for rheumatoid arthritis. FEBS Lett. 388: 161-164.

Halliwell B (1994). Free radicals, antioxidants, and human disease: curiosity, cause, or consequence? Lancet 344: 721-724.

Humbert R, Adler DA, Disteche CM, Hassett C, et al. (1993). The molecular basis of the human serum paraoxonase activity polymorphism. Nat. Genet. 3: 73-76.

Isik A, Koca SS, Ustundag B, Celik H, et al. (2007). Paraoxonase and arylesterase levels in rheumatoid arthritis. Clin. Rheumatol. 26: 342-348.

Jaswal S, Mehta HC, Sood AK and Kaur J (2003). Antioxidant status in rheumatoid arthritis and role of antioxidant therapy. Clin. Chim. Acta 338: 123-129.

Leduc V and Poirier J (2008). Polymorphisms at the paraoxonase 1 L55M and Q192R loci affect the pathophysiology of Alzheimer's disease: emphasis on the cholinergic system and beta-amyloid levels. Neurodegener. Dis. 5: 225-227.

Leduc V, Theroux L, Dea D, Robitaille Y, et al. (2009). Involvement of paraoxonase 1 genetic variants in Alzheimer's disease neuropathology. Eur. J. Neurosci. 30: 1823-1830.

Mackness B, Mackness MI, Arrol S, Turkie W, et al. (1998). Effect of the human serum paraoxonase 55 and 192 genetic polymorphisms on the protection by high density lipoprotein against low density lipoprotein oxidative modification. FEBS Lett. 423: 57-60.

Mackness MI, Mackness B, Durrington PN, Connelly PW, et al. (1996). Paraoxonase: biochemistry, genetics and relationship to plasma lipoproteins. Curr. Opin. Lipidol. 7: 69-76.

Maury CP, Junge W and Teppo AM (1984). Serum esterase activity in reactive systemic amyloidosis and its relation to amyloid A degrading activity. J. Lab. Clin. Med. 104: 761-766.

McKeown MJ, Hall ND and Corvalan JR (1984). Defective monocyte accessory function due to surface sulphydryl (SH) oxidation in rheumatoid arthritis. Clin. Exp. Immunol. 56: 607-613.

Miesel R, Murphy MP and Kroger H (1996). Enhanced mitochondrial radical production in patients which rheumatoid arthritis correlates with elevated levels of tumor necrosis factor alpha in plasma. Free Radic. Res. 25: 161-169.

Newton CR, Graham A, Heptinstall LE, Powell SJ, et al. (1989). Analysis of any point mutation in DNA. The amplification refractory mutation system (ARMS). Nucleic Acids Res. 17: 2503-2516.

Nurcombe HL, Bucknall RC and Edwards SW (1991). Activation of the neutrophil myeloperoxidase- $\mathrm{H}_{2} \mathrm{O}_{2}$ system by synovial fluid isolated from patients with rheumatoid arthritis. Ann. Rheum. Dis. 50: 237-242.

Popa C, van Tits LJ, Barrera P, Lemmers HL, et al. (2009). Anti-inflammatory therapy with tumour necrosis factor alpha inhibitors improves high-density lipoprotein cholesterol antioxidative capacity in rheumatoid arthritis patients. Ann. Rheum. Dis. 68: 868-872.

Primo-Parmo SL, Sorenson RC, Teiber J and La Du BN (1996). The human serum paraoxonase/arylesterase gene (PON1) is one member of a multigene family. Genomics 33: 498-507.

Rozenberg O, Rosenblat M, Coleman R, Shih DM, et al. (2003). Paraoxonase (PON1) deficiency is associated with increased macrophage oxidative stress: studies in PON1-knockout mice. Free Radic. Biol. Med. 34: 774-784.

Saremi MA, Saremi M and Tavallaei M (2008). Rapid genomic DNA extraction (RGDE). Forensic Sci. Int. Genet. Suppl. Ser. 1: 63-65.

Sattar N, McCarey DW, Capell H and McInnes IB (2003). Explaining how "high-grade" systemic inflammation accelerates vascular risk in rheumatoid arthritis. Circulation 108: 2957-2963.

Shih DM, Gu L, Xia YR, Navab M, et al. (1998). Mice lacking serum paraoxonase are susceptible to organophosphate toxicity and atherosclerosis. Nature 394: 284-287.

Sidoti A, Antognelli C, Rinaldi C, D’Angelo R, et al. (2007). Glyoxalase I A111E, paraoxonase 1 Q192R and L55M polymorphisms: susceptibility factors of multiple sclerosis? Mult. Scler. 13: 446-453.

Tanimoto N, Kumon Y, Suehiro T, Ohkubo S, et al. (2003). Serum paraoxonase activity decreases in rheumatoid arthritis. Life Sci. 72: 2877-2885.

Ye S, Dhillon S, Ke X, Collins AR, et al. (2001). An efficient procedure for genotyping single nucleotide polymorphisms. Nucleic Acids Res. 29: E88. 